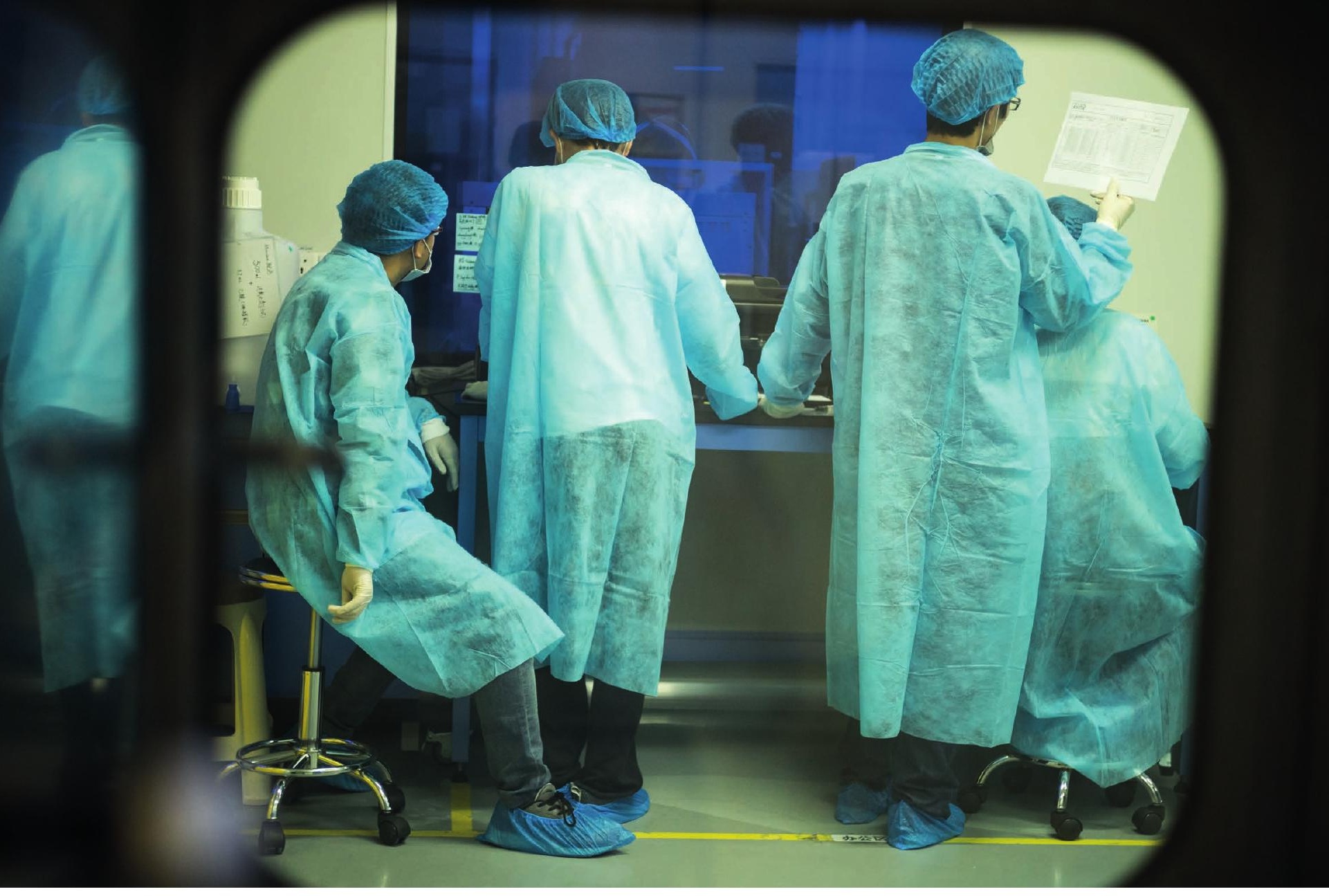

\title{
THE SEQUENCING SUPERPOWER
}

\author{
First China conquered DNA sequencing. \\ Now it wants to dominate precision medicine too.
}

BY DAVID CYRANOSKI

0 ix years ago, China became the global leader in DNA sequencing — and it was all down to one company, BGI. The Shenzenbased firm had just purchased 128 of the world's fastest sequencing machines and was said to have more than half the world's capacity for decoding DNA. It was assembling an army of upstart young bioinformaticians, collaborating with leading researchers worldwide and publishing the sequences of creatures ranging from ancient humans to the giant panda. The firm was quickly gaining a reputation as a brute-force genome factory - more brawn than brains, said some.

Six years later, the scene is quite different. BGI's most famous scientist and visionary leader, Jun Wang, left last July. The machine that had given the company its dominance is outdated, and the firm's attempt to develop its own industrial-scale whole-genome sequencer hit a roadblock last November, forcing it to lay off employees at its US subsidiary. Meanwhile, the competing system - Illumina's X series has been selling briskly, raising the speed and dropping the price of sequencing worldwide.

Armed with the latest sequencers, rival companies to BGI have emerged. Most prominent of these is Novogene in Beijing, founded in 2011 by former BGI vice-president Ruiqiang Li. And although BGI might not have the uncontested dominance it once did, it still claims to have the world's largest sequencing capacity as well as major scientific ambitions - including to sequence the genomes of one million people, one million plants and animals and one million microbial ecosystems. Today, China is being reborn as a

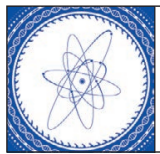

\section{SCIENCE IN CHINA A Nature collection nature.com/chinafocus}

sequencing power with a broader base.

Fuelling the drive is a multibillion-dollar, 15-year precision-medicine initiative, which China announced in March and which rivals a similar initiative in the United States. If these efforts fulfil their goals, doctors envision being able to use a person's genome and physiology to pick the best treatments for his or her disease. The goal now for sequencing companies is to turn the bounty of genomic data into medical benefits.

To do that, sequence data alone are not enough - so some Chinese companies are going beyond brute-force sequencing to work out how lifestyle factors such as diet are also important for understanding disease risk and for finding therapies. "The thing about China is the ambition they have for their precision-medicine programme is orders of magnitude larger than the United States,' says Hannes Smárason, chief operating officer and co-founder of 
Scientists at

sequencing giant

BGI in Shenzhen are

looking to apply their

genetic expertise to

medicine.
WuXiNextCODE,

a genomics com-

pany in Cambridge,

Massachusetts, that

is part of Shanghai-

based WuXi AppTec.

"They are dynamic

and receptive. There, the idea of integrating of genomics into health care is very real."

\section{RISE OF THE MACHINE}

The new energy behind sequencing is largely thanks to one machine: Illumina's HiSeq X Ten, so called because it is generally sold as sets of ten units. When the machine hit the market in 2014, one set was able to sequence a human genome for close to US $\$ 1,000$, and power through some 18,000 human genomes per year. Companies that wanted to rival BGI saw an opportunity - and leapt.

Novogene was the first. Following a model similar to BGI's, Li has been building up a large staff of bioinformaticians to generate and interpret sequence data as part of collaborative basicresearch projects on the snub-nosed monkey (Rhinopithecus roxellana) ${ }^{1}$, cotton (Gossypium hirsutum $)^{2}$ and other plants and animals. Using the same machine, a handful of other companies - including WuXi PharmaTech and Cloud Health, both in Shanghai - focus more on offering sequencing as a service to pharmaceutical or personal-genomics companies.

The growth is accelerating. Novogene added a second X Ten set in April, and Cloud Health chief executive Jason Gang Jin says that the company will add another two sets this year. By the end of the year, China will probably have at least 70 units. (Illumina says that 300 units were sold worldwide by the end of last year.)

BGI has been trying to keep pace. In 2013, it purchased Complete Genomics in Mountain View, California, in a bid to create its own advanced sequencing machines for in-house use and for sale. The firm announced a system called Revolocity, its attempt to match the HiSeq X, last June. But in November, having taken just three orders, it suddenly suspended sales. BGI is now left with its ageing fleet of 128 Illumina HiSeq 2000 machines and a mélange of newer sequencers from various companies, including its own.

Estimates of China's share of the world's sequencing-capacity range from $20 \%$ to $30 \%$ - still lower than when BGI was in its heyday, but expected to increase fast. "Sequencing capacity is rising rapidly everywhere, but it's rising more rapidly in China than anywhere else," says Richard Daly, chief executive of DNAnexus in Mountain View, which supplies cloud platforms for large-scale genomics.

BGI has another machine up its sleeve. The BGISEQ-500 is designed as more of a desktop instrument for research labs. It is also based on the Complete Genomics technology and is set to begin shipping this year. Yiwu He, BGI's new global head of research, says that the system can sequence a human genome for $\$ 1,000$, and by being smaller in scale and more flexible to use, it will meet China's emerging need for clinical sequencing. "There will be more sequencing done outside of research institutes, in the hospitals," says He. The company will bring the price of one human genome sequence down to $\$ 200$ in the next few years, he predicts boldly. "China is the most exciting place to do biomedical research."

\section{GENOMES EN MASSE}

The announcement of the precision-medicine programme sent a ripple of excitement through China's sequencing giants. The money will be spent on improving technologies, sequencing, and sharing and analysing more than one million human genomes, as well as on developing drugs and diagnostics from the data and using those findings to personalize medical care. Hungry for a share of the cash, hospitals and clinicians are teaming up with sequencing companies to come up with proposals for the work.

The one million human genomes will be split among a variety of studies, and will include groups of 50,000 people who each have metabolic disease, breast cancer, gut cancer or another condition. There will also be cohorts else in the world, predicts He. "We can get there faster because of our partnership with the government, hospitals, universities, because we can move faster than large consortia, and particularly because we have our own sequencer. That is a huge advantage," he says.

But making sense of one million human genomes is a major challenge, says Wang, who quit BGI to found a company called iCarbonX in Shenzhen. The firm plans to collect sequencing data for more than a million people "as a start", as well as other biological information, including changes in levels of proteins and metabolites, brain imaging, biosensors to monitor things such as glucose levels and even the use of smart toilets that will allow real-time monitoring of urine and faeces. Wang calls it a "digital form of you". He plans to use artificial intelligence to integrate all the data, with the ultimate aim of providing medical care that is tuned to an individual's genes and physiological state. Less than a year in, Wang has raised more than $\$ 100$ million, including a big chunk from Shenzen-based Tencent, the company behind the social-media application WeChat, which Wang says will help to build the datacollection platform.

\section{"SEQUENCING CAPACITY IS RISING RAPIDLY EVERYWHERE, BUT IT'S RISING MORE RAPIDLY IN CHINA THAN ANYWHERE ELSE.}

that represent northern, central and southern China, "to look at the different genetic backgrounds of subpopulations", says Li.

Similar projects exist elsewhere, including one in the United Kingdom that is sequencing 100,000 genomes, and one in the United States that has a budget of $\$ 215$ million and aims to cover one million genomes. But China will have some advantages, observers say, not least of which is firm backing from the government. Over the next five years, the government has promised to add several precision drugs and molecular-diagnosis products to the national medical-insurance list, ensuring that companies' research costs will be recouped if they lead to such a product. In the United States, biotech companies with new products can struggle to get insurance companies or the government to pay. "There is greater acceptance of sequencing and willingness to invest in it in China," says Daly.

In September, BGI will open the China National Genebank, a five-hectare facility in Shenzhen that will house millions of samples from people, animals, plants and microbes. Entrusted to BGI by the central government, the bank will make some samples and data available to researchers around the world. And the company is compiling its own database of one million human genomes, which will overlap to some degree with the national project. BGI will hit the target before anyone
China is already exploring how else genomics can benefit health. In March, BGI celebrated its one millionth NIFTY test - a screen that sequences fetal DNA circulating in the mother's blood to detect chromosomal abnormalities such as Down's syndrome ${ }^{3}$. The country's conversion from a one-child to two-child policy is expected to accelerate the demand for such tests. Cancer genetics is also well on its way. Cloud Health last year fed genomic data from some 15,000 tumour samples to more than 100 genetics companies in China to help with diagnosis and make sure that patients get the right chemotherapy drugs. The market for pricey genomic tests is growing in step with the country's middle class. "China has 100 million people making more than $\$ 50,000$ now," says Daly.

For Wang, sequencing on its own is old hat. "Genomics is important, but it's just one piece of the puzzle," he says. "All the complex traits. All the neurodegenerative disorders, cancer, diabetes - it's all more than genetics. If we only talk about genomics, about massive data without clinical info, that's not enough."

David Cyranoski writes for Nature from Shanghai, China.

1. Zhou, X. et al. Nature Genet. 46, 1303-1310 (2014).

2. Zhang, T. et al. Nature Biotechnol. 33, 531-537 (2015).

3. Dan, S. et al. Prenat. Diagn. 32, 1225-1232 (2012). 